\title{
Functional Outcome of Patients Undergoing Volar Buttress Plate for Fixation in Volar Barton's Fracture of the Distal Radius
}

\author{
Islam $\mathrm{MA}^{1^{*}}$, Kumar $\mathrm{N}^{2}$, Haque $\mathrm{R}^{3}$, Barmon $\mathrm{SC}^{4}$, Shahidullah $\mathrm{M}^{5}$, Forhad $\mathrm{S}^{6}$, Alam $\mathrm{S}^{7}$, Kundu $\mathrm{S}^{8}$
}

\begin{abstract}
${ }^{1}$ Dr. Mohammed Amirul Islam, Resident Surgeon Casualty (Current Charge), Sher-E-Bangla Medical College Hospital (SBMCH), Barishal, Bangladesh

${ }^{2}$ Professor Nakul Kumar, Professor \& Ex-Chairman, Bangabandhu Sheikh Mujib Medical University (BSMMU), Dhaka, Bangladesh ${ }^{3}$ Dr. Rashedul Haque (Junior Consultant), Department of Orthopaedics, Pabna 250 Bed General Hospital, Pabna, Bangladesh

${ }^{4}$ Dr. Shamol Chondra Barmon (Junior Consultant), Department of Orthopedic Surgery, Sunamganj 250 Bed District Sadar Hospital.Sunamgonj, Bangladesh

${ }^{5}$ Dr. Md. Shahidullah, Assistant Professor, Department of Orthopaedics, Kushtia Medical College, Kushtia, Bangladesh

${ }^{6}$ Dr. Sheikh Forhad, Department of Orthopaedicsurgery, Bangabandhu Sheikh Mujib Medical University, Dhaka, Bangladesh

${ }^{7}$ Dr. Shamsul Alam, Department of Orthopaedic,Gazaria Upazila Health Complex,Munshigonj, Bangladesh

${ }^{8}$ Dr. Sujit Kundu (Junior Consultant). Department of Orthopedic Surgery, National Institute of Traumatology \& Oethopaedic Rehabilitation (NITOR), Dhaka, Bangladesh
\end{abstract}

DOI: $10.36347 /$ sasjs.2022.v08i01.003

| Received: 31.11.2021 | Accepted: 03.01.2022 | Published: 10.01.2022

*Corresponding author: Dr. Mohammed Amirul Islam

Resident Surgeon (Current Charge), Sher-E-Bangla Medical College Hospital (SBMCH), Barishal, Bangladesh

\section{Abstract}

Original Research Article

Introduction: Volar Barton's fracture is a common problem among the distal radius fracture. Shearing fractures may involve the Volar articular margin is a displaced and inherently unstable fracture that may lead to pain, deformity, limited range of motion, and loss of hand function. In clinical practices, various methods are used for the management of Volar Barton's fractures. The Volar buttress plate technique is now mostly chosen for the management of this type of fracture. The aim of the study was to observe the functional outcome of treating a Volar Barton's fracture of the distal radius using a buttress plate. Methods: This prospective interventional study was carried out in the Department of Orthopaedic Surgery, BSMMU, Shahbag, Dhaka for the duration of 2 years 6 months (March 2014 to September 2016). Within this period 30 patients of Volar Barton's fracture were selected as per inclusion and exclusion criteria who are admitted in this institution. After proper evaluation of these patients, open reduction and internal fixation were done with Volar locking buttress plate. Result: In this study, out of 30 patients $77 \%$ were male and $23 \%$ were female where the mean age was $32 \pm 9.3$ and maximum incidence was between 18-39 years. Left side involvement was more $63 \%$ (19 patients) than right side involvement at 37\% (11 patients). $7 \%$ of patients were found with superficial skin infections and treated non-operatively. In the final follow-up, $6.7 \%$ were obtained excellent scores, $73.3 \%$ were obtained good scores and $20 \%$ were obtained fair scores on the basis of anatomical outcome. Conclusion: The Volar buttress plate is found an effective technique of fixation. The Volar locking buttress plate maintained articular congruity, radial length, and alignment. The significant functional outcomes were observed at end of the final followup (24 weeks).

Keywords: Fracture, Distal, Volar, Buttress.

Copyright $(\mathcal{2 0 2 2}$ The Author(s): This is an open-access article distributed under the terms of the Creative Commons Attribution 4.0 International License (CC BY-NC 4.0) which permits unrestricted use, distribution, and reproduction in any medium for non-commercial use provided the original author and source are credited.

\section{INTRODUCTION}

Distal radius fractures range from simple fractures that require conservative treatment, to severe multi-fragmented fracture-dislocations that are difficult to handle. However, distal radius fractures are more likely to include the radiocarpal and/or distal radioulnar joints. They can be either partly articular or fully articular. In order to lower the incidence of posttraumatic arthritis and produce a favorable functional result, the joint surface must be anatomically reduced. As a result, intra-articular fractures such as Barton's fracture frequently requires surgical therapy as well as an internal fixation with a buttress plate [1, 2]. Changing the notion of distal radius fracture categorization, findings, treatment, prognosis, and management is necessary, and it needs distinguishing low-energy metaphyseal injuries (Colles' fracture) from more severe injuries that alter the articular surfaces (Barton's fracture). Articular injuries are more typically 
comminuted and unstable, making the more common conventional treatment methods of closure reduction and cast immobilization less suitable. Skeletal fixation and re-alignment of fracture fragments, on the other hand, are the superior options. Furthermore, malunion is common, and may result in discomfort, reduced range of motion, weakening, and traumatic arthritis of the wrist [3]. A fall on the outstretched hand from standing height is the most common cause of injury that results in a fracture in the comminuted distal radius, albeit a small percentage of patients will develop significant energy damage. Clinician-measured outcomes are based on grip strength, ranges of motion, functional status, and pain at the fracture site [4]. Unstable distal radius fractures are mechanically prone to re-displacement following closed manipulation. Several causes have been linked to the instability. These are some examples: Initial fracture displacement, patient age, level of metaphyseal comminution, amount of intra-articular comminution and steps, and ultimately displacement following conservative treatment are all predictors of instability, and recurrent manipulation is unlikely to result in a satisfactory radiographic outcome [5]. Although it was previously believed that extra-articular fractures occur among the elder population only, that has since been proven wrong and it was observed that both intra-articular and extra-articular fractures are involved in younger and older patients alike. Barton's fracture is a common unstable fracture that requires open reduction and internal fixation with a tiny buttress plate. Several publications have observed that internal fixation efficiently recovers articular congruency $[6,7]$ Incorrect fracture reduction results in intra-articular incongruency or carpal change, which may have an impact on the surgical outcome [8-10]. As a result, the precise surgical outcome is dependent on the proper reduction of distal radius fractures rather than the use of fixing procedures. The capacity to reposition the large displaced fracture pieces is a significant benefit of internal fixation. The optimal management of distal radius fractures has changed radically over the previous two decades from almost universal use of cast immobilization to a variety of highly sophisticated operative interventions. The recent trend in most unstable intraarticular fractures is to treat surgically. Internal fixation of potentially unstable distal radial fractures using a Volar plate was demonstrated to increase the likelihood of painless union over conservative treatment methods [11].

\section{OBJECTIVE}

\section{General Objective}

- To evaluate the functional improvement of the wrist after operation.

\section{METHODS}

This prospective interventional study was conducted at the Department of Orthopaedic Surgery, Bangabandhu Sheikh Mujib Medical University (BSMMU), Shahbag, Dhaka, Bangladesh during the 2 years of March 2014 to September 2016. The initial sample size was assumed to be 384 , according to a mathematical equation, but due to the unavailability of patients, the revised sample size was selected as 30 . The patients were selected from those attending the orthopedic emergency and outpatient department of the study hospital, following a Purposive type of nonprobability sampling technique as per the exclusion and inclusion criteria. A questionnaire was prepared beforehand for the collection of data. Sarmiento and Latta (1980) scoring system was used for patient outcome categorization [12]. Informed written consent was obtained from each participant, and ethical approval was obtained from the ethical review committee of the hospital.

\section{Inclusion Criteria}

- Closed Volar Barton's fracture of the distal radius (AO/ASIF type B3)

- Recent cases (within 3 weeks)

- Age 18 to 60 years

- Both Sexes

\section{Exclusion Criteria}

- Open wound.

- Volar Barton's fracture more than 3 weeks.

- Associated Infection

- Associated fracture in ipsilateral upper limb

- Noncooperative patient

\section{RESULTS}

Table-1: Age distribution of the participants $(n=30)$

\begin{tabular}{|l|l|l|}
\hline Age (Years) & Frequency & Percentage \\
\hline $18-39$ & 22 & $73 \%$ \\
\hline $40-64$ & 8 & $27 \%$ \\
\hline Mean \pm SD (Min-Max) & $\begin{array}{l}32 \pm 9.3 \\
(19-60)\end{array}$ & \\
\hline
\end{tabular}

The maximum of $22(73 \%)$ patients were found in the age group 18-39 years, and a minimum of $8(27 \%)$ patients were found in the age group of 40-64 years, respectively. The mean $\pm \mathrm{SD}$ age of the participants was $32 \pm 9.3$, and the range of the participants was 19 to 60 years. 


\section{Gender Distribution}

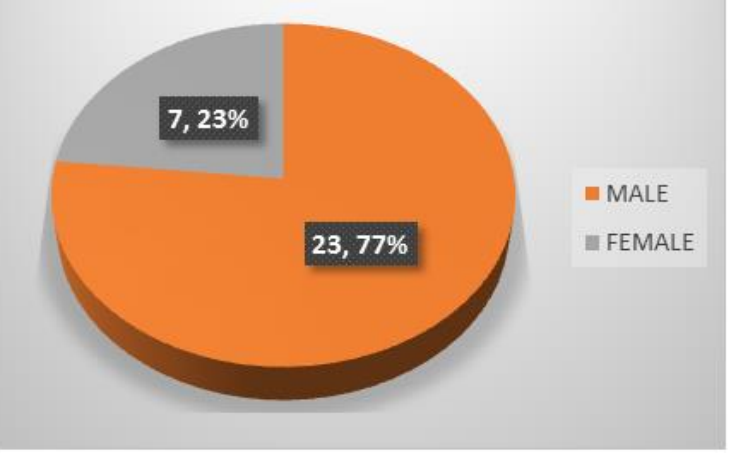

Fig-1: Gender distribution of the participants $(n=30)$

Out of 30 patients, $23(77 \%)$ patients were male and 7 (23\%) patients were female. Male: Female ratio was $3.3: 1$.

Table-2: Distribution of participants by side of injury $(\mathbf{n}=30)$

\begin{tabular}{|l|l|l|}
\hline Sides of Injury & Frequency & Percentage \\
\hline RIGHT & 11 & $37 \%$ \\
\hline LEFT & 19 & $63 \%$ \\
\hline
\end{tabular}

Out of the 30 patients, $11(37 \%)$ patients were injured on the right side, and the remaining majority of $19(63 \%)$ patients were injured on the left side.

Table-3: Distribution of participants by time interval between injury and management $(n=30)$

\begin{tabular}{|l|l|l|}
\hline Time interval (weeks) & Frequency & Percentage \\
\hline$<1$ & 24 & $80 \%$ \\
\hline $1-2$ & 2 & $7 \%$ \\
\hline $2-3$ & 4 & $13 \%$ \\
\hline
\end{tabular}

For $24(80 \%)$ of the participants, the time between injury and its management was $<1$ week. The time interval was between 1-2 weeks for $2(7 \%)$ of the participants, and between 2-3 weeks for $4(13 \%)$ of the participants.

Table-4: Distribution of participants by Associated injury $(\mathbf{n}=\mathbf{3 0})$

\begin{tabular}{|l|l|l|}
\hline Associated Injury & Frequency & Percentage \\
\hline Fracture NOF & 2 & $7 \%$ \\
\hline Fracture SOF & 1 & $3 \%$ \\
\hline None & 27 & $90 \%$ \\
\hline
\end{tabular}

Among the total 30 participants, only 3 participants had an associated injury along with volar burtons fracture. $2(7 \%)$ patients had fractured NOF (Neck of Femur) and 1 (3\%) patient had fractured SOF (Shaft of Femur) type of associated injury.

Table-5: Distribution of participants by duration of hospital stay $(n=30)$

\begin{tabular}{|l|l|l|}
\hline Hospital stay (Day) & Frequency & Percentage \\
\hline $1-2$ & 5 & $17 \%$ \\
\hline $3-4$ & 16 & $53 \%$ \\
\hline $5-6$ & 7 & $23 \%$ \\
\hline $7-8$ & 2 & $7 \%$ \\
\hline Total & 30 & $100 \%$ \\
\hline
\end{tabular}

The majority of the patients $(93 \%)$ had to stay in hospital for less than a week and $7 \%$ of patients had to stay more than a week during open reduction. $53 \%$ of the participants stayed between 3-4 days, while 23\% stayed between 5-6 days, and 17\% stayed in the hospital for only 1 or 2 days.

Table-6: Distribution of participants by post-operative complications $(n=30)$

\begin{tabular}{|l|l|l|}
\hline Complications & Frequency & Percentage \\
\hline Superficial wound infection & 2 & $7 \%$ \\
\hline Wrist stiffness & 1 & $3 \%$ \\
\hline Carpal tunnel syndrome & 1 & $3 \%$ \\
\hline Late collapse & 1 & $3 \%$ \\
\hline None & 25 & $83 \%$ \\
\hline Total & 30 & $100 \%$ \\
\hline
\end{tabular}

Only 5 out of $30(17 \%)$ participants showed some sort of complication after the surgery. Superficial wound infection was observed in $2(7 \%)$ of the cases, wrist stiffness, carpal tunnel syndrome, and late collapse was each observed in $3 \%$ of the cases.

Table-7: Distribution of participants by functional outcome grading at final follow-up $(\mathrm{n}=30)$

\begin{tabular}{|l|l|l|l|l|l|}
\hline \multirow{2}{*}{ Grade } & & \multicolumn{2}{|l|}{ Satisfactory } & Unsatisfactory \\
\cline { 3 - 6 } & & Excellent & Good & Fair & Poor \\
\hline \multirow{2}{*}{ Pre-operative } & Frequency & - & - & 4 & 26 \\
\cline { 2 - 6 } & Percentage & - & - & $13.30 \%$ & $86.70 \%$ \\
\hline \multirow{2}{*}{ Final Follow-up } & Frequency & 2 & 22 & 6 & - \\
\cline { 2 - 6 } & Percentage & $6.70 \%$ & $73.30 \%$ & $20.00 \%$ & - \\
\hline
\end{tabular}


During pre-operative grading of the functional outcome, $4(13.30 \%)$ of the participants graded their functionality as fair, and the remaining $26(86.70 \%)$ of cases graded their functionality as poor. After the surgery, during the final follow-up, $2(6.70 \%)$ cases graded their functionality as excellent, while 22 $(73.30 \%)$ of the cases graded them as good. The remaining $6(20 \%)$ graded their functional outcome as fair. In total, $24(80 \%)$ of cases had satisfactory and 6 (20\%) had unsatisfactory outcomes during their final surgery. The functional outcome was graded according to the Sarmiento and Latta (1980) scoring system [12].

\section{DISCUSSION}

Barton's fracture is a distal radius fracture that extends through the dorsal aspect of the articular surface with associated radiocarpal joint dislocation; however, because the radiocarpal ligaments are not disrupted, the articular surface of the fractured distal radius remains in contact with the proximal carpal row [13]. Volar Barton's fracture, is named after the American surgeon John Rhea Barton. Shearing fractures may involve the Volar or dorsal articular margin (Barton's fractures), the radial styloid, or the lunate facet of the distal radius. These partial articular fractures are inherently unstable. Failure to realign the fragment risks of subluxation of the carpus. For this reason, shearing fractures are most preferably treated with open reduction and plate and screw fixation [14]. In the present study, the majority of Volar Barton's cases were in patients aged between 18-39 years. Age factors related to the characteristics of the wrist and distal radius fractures were stated by several studies [15-17]. They have surmised that between the age of 18-39 years as young adults, the fracture is often a result of higher energy or sports, while in participants aged between 40-64 years, the fracture incidence is higher among the female population compared to the male, while in patients aged 65 or older, the incidence of such fracture cases is higher among the male population. In the present study, $77 \%$ were male, and only $23 \%$ were female. This high male prevalence was linked to the higher incidence of cases among young adults and the cause of such injuries. The male: female ratio in our study was $3.3: 1$, which was similar to another study with the male: female ratio of $3: 1$ [18]. Among the injuries, $37 \%$ were on the right arm, while the remaining $63 \%$ were on the left arm. The time interval between injury and management was less than 1 week for $80 \%$ of cases. This resulted in an overall better outcome. Only 2 cases had 1-2 weeks between injury and management, while 4 cases had between 2-3 weeks from initial injury to management or treatment. The volar locked plating technique has become the preferred method because of its ability to stabilize the unstable fractures and efficient fixations performance [19-21] 3 of the participants had additional injuries alongside the distal radius fracture. 2 participants had fractured neck of femur, and 1 participant had fractured shaft of femur. The distal radius fracture is a common injury of the wrist. But the best treatment method is not yet established. Some degree of displacement or redisplacement, and emphasis placed on function, are often accepted while treated conservatively [22]. The participants of the present study were treated using a locked buttress plate, and after the operation, the majority of the participants had hospital stays lasting 36 days. In this study, $7 \%$ of the participants had superficial skin infections and were treated nonoperatively. A previous study found the volar locking plating system was associated with a short-term complication rate of $10 \%$, which was slightly higher than our study. The participants of the present study also faced some other forms of complications, but $83 \%$ of the participants faced no complications after their operation. At the final follow-up, all patients were functionally assessed according to the Sarmiento and Latta (1980) scoring system [12]. The functional outcome showed that $20 \%$ of the participants graded unsatisfactory results, while $80 \%$ showed satisfactory functional outcomes.

\section{Limitations of The Study}

The study was conducted in a single hospital with very small sample size. So, the results may not represent the whole community. Follow up period in this study was short. So, very late post-operative complications could not be evaluated.

\section{CONCLUSION}

The Volar Barton's fracture of the distal radius is relatively very unstable in nature and difficult to treat with a conservative method of treatment. However, the functional outcome of a Volar Barton's fracture of distal radius treated with a buttress plate is highly satisfactory and statistically significant.

\section{RECOMMENDATION}

A similar type of study should be performed on larger sample size. Follow-up of a similar type of study should be done in a longer period. Specialized training program for the general practitioner at rural areas for early diagnosis early management and referral system for better and early treatment.

\section{Funding: Self}

Conflict of interest: None declared

Ethical approval: The study was approved by the Institutional Ethics Committee

\section{REFERENCES}

1. Melone, C.P. (1984). 'Articular fractures of the distal radius', Orthop Clin North Am, 15, 217-236

2. Knirk, J.L., \& Jupiter, J.B. (1986). 'Intra-articular fractures of the distal end of the radius in young adults', J Bone Joint Surg Am, 68(5), 647-659

3. Rettig, M.E., Raskin, K.B., \& Melone, C.P. (1997). Fractures of the distal radius. In: Lichtman DM, 
Alexander AH (eds), The Wrist and Its Disorders, 2nd ed. Philadelphia, PA:WB Saunders

4. Lozano-Calderón, S.A., Souer, S., Mudgal, C., Jupiter, J.B., Ring, D. (2008). Wrist mobilization following volar plate fixation of fractures of the distal part of the radius. JBJS. 1;90(6):1297-304.

5. Orbay, J.L., Touhami, A. (2006). Current concepts in volar fixed-angle fixation of unstable distal radius fractures. Clinical Orthopaedics and Related Research (1976-2007). 1;445:58-67.

6. Arora, J, \& Malik, A.C. (2005). 'External fixation in comminuted, displaced intra-articular fractures of the distal radius: is it sufficient', Arch Orthop Trauma Surg, 125(8), 536-540.

7. Y, Kim, M.D., \& Melvin, P.R. (2007). 'Internal Fixation of Distal Radius Fractures', A Supplement to the American Journal of Orthopedics, 36, 121; 27

8. Trumble, T. E., Schmitt, S. R., \& Vedder, N. B. (1994). Factors affecting functional outcome of displaced intra-articular distal radius fractures. The Journal of hand surgery, 19(2), 325-340.

9. Knight, D., Hajducka, C., Will, E., \& McQueen, M. (2010). Locked volar plating for unstable distal radial fractures: clinical and radiological outcomes. Injury, 41(2), 184-189.

10. Kreder, H. J., Hanel, D. P., Agel, J., McKee, M., Schemitsch, E. H., Trumble, T. E., \& Stephen, D. (2005). Indirect reduction and percutaneous fixation versus open reduction and internal fixation for displaced intra-articular fractures of the distal radius: a randomised, controlled trial. The Journal of bone and joint surgery. British volume, 87(6), 829-836.

11. Koenig, K. M., Davis, G. C., Grove, M. R., Tosteson, A. N., \& Koval, K. J. (2009). Is early internal fixation preferred to cast treatment for well-reduced unstable distal radial fractures?. JBJS, 91(9), 2086-2093.

12. Sarmiento, A., Zagorski, J. B., \& Sinclair, W. F. (1980). Functional bracing of Colles' fractures: a prospective study of immobilization in supination vs. pronation. Clinical orthopaedics and related research, (146), 175-183.

13. Shander, A., Fink, A., Javidroozi, M., Erhard, J., Farmer, S. L., Corwin, H., ... \& Spahn, D. R.
(2011). Appropriateness of allogeneic red blood cell transfusion: the international consensus conference on transfusion outcomes. Transfusion medicine reviews, 25(3), 232-246.

14. Gupta, K., Gaonkar, N., Sudhir, K. J., Patel, N., Koli, V., Date, S., ... \& Chanchpura, G. (2015). To compare functional outcome, complications and results of open reduction and internal fixation with closed reduction and external fixation in volar displaced distal radial fractures.

15. Harness, N., Ring, D., \& Jupiter, J. B. (2004). Volar Barton's fractures with concomitant dorsal fracture in older patients. The Journal of hand surgery, 29(3), 439-445.

16. Putnam, M. D. (2000). Smith's and Volar Barton's Fractures. In Management of Fractures in Severely Osteoporotic Bone (pp. 190-205). Springer, London.

17. Harish, P., Girish, K.K., Sudheendra, P.R., Harminder, S. (2016). 'Functional results and complications of displaced intra articular distal radius fracture treated by volar plates', Journal of Science, 6(1), 1-4

18. Liporace, F. A., Gupta, S., Jeong, G. K., Stracher, M., Kummer, F., Egol, K. A., \& Koval, K. J. (2005). A biomechanical comparison of a dorsal 3.5-mm T-plate and a volar fixed-angle plate in a model of dorsally unstable distal radius fractures. Journal of orthopaedic trauma, 19(3), 187-191.

19. Martineau, P. A., Berry, G. K., \& Harvey, E. J. (2007). Plating for distal radius fractures. Orthopedic Clinics of North America, 38(2), 193-201.

20. Chen, N. C., \& Jupiter, J. B. (2007). Management of distal radial fractures. JBJS, 89(9), 2051-2062.

21. Sarmiento, A., Pratt, G. W., Berry, N. C., \& Sinclair, W. F. (1975). Colles' fractures. Functional bracing in supination. The Journal of bone and joint surgery. American volume, 57(3), 311-317.

22. Chung, K. C., Watt, A. J., Kotsis, S. V., Margaliot, Z., Haase, S. C., \& Kim, H. M. (2006). Treatment of unstable distal radial fractures with the volar locking plating system. JBJS, 88(12), 2687-2694. 